\title{
Membudayakan Patient Safety sebagai bentuk dari Organisasi Reform \\ dalam Mencegah Human Err
}

Balqis Fadillah*, Syifa Atun Nisa**

[KMPK IKM UGM*]

\section{AIM / OBJECTIVE}

Patient safety merupakan komponen kritis dari mutu pelayanan kesehatan. Isu terkait patient safety diantaranya medical errors dan diagnostic errors. Berbagai studi melaporkan bahwa kasus diagnostic errors dan medical errors di fasilitas pelayanan kesehatan terjadi di seluruh negara, tidak terkecuali di negera berkembang seperti Indonesia.

Rumah sakit sebagai organisasi pelayanan kesehatan, seharusnya menumbuhkan budaya patient safety untuk mencegah terjadinya human err yang berdampak pada medical errors dan diagnostic errors. Namun pada kenyataannya penerapan budaya patient safety masih sangat sulit diterapkan di beberapa rumah sakit, contohnya di salah satu rumah sakit di Kota Jambi. Berdasarkan studi yang dilakukan, diketahui bahwa masih terjadi human err berupa diagnostic errors yaitu kesalahan penegakan diagnosis dan medical errors yang berupa kesalahan dalam penjahitan luka. Hal ini disebabkan karena belum optimalnya penerapan budaya patient safety di rumah sakit tersebut.
Medical errors seperti Kejadian yang Tidak Diinginkan (KTD) menjadi salah satu kasus yang sering terjadi. Fenomena ini seperti gunung es, dimana kasus - kasus yang serius dan mengancam jiwa secara mudah tampak di permukaan, sedangkan kasus - kasus yang sifatnya ringan sampai sedang umumnya tidak terdeteksi, tidak dicatat, ataupun tidak dilaporkan.

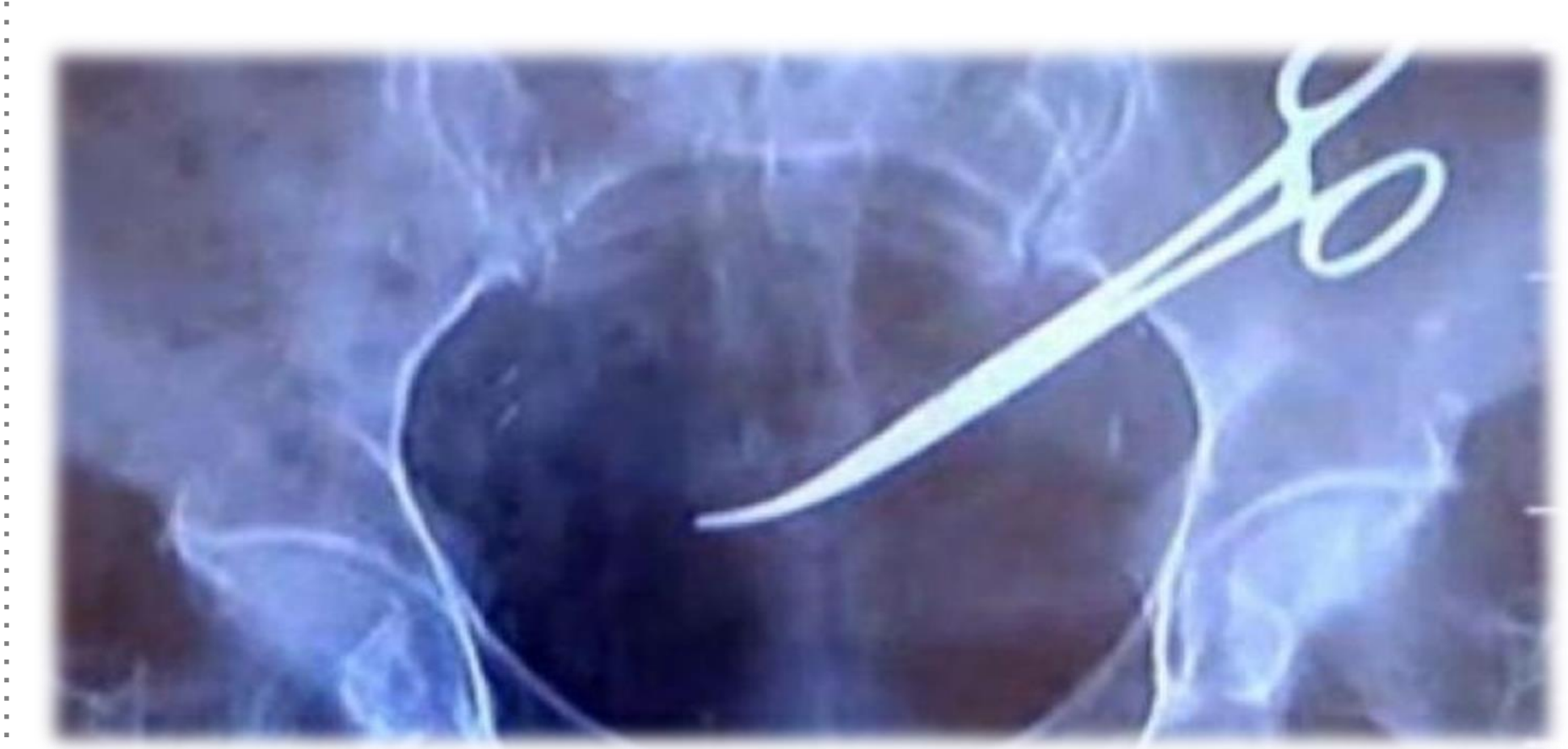

\section{LESSON LEARN}

1. Budaya patient safety merupakan pilar gerakan keselamatan pasien di pelayanan kesehatan.

2. Rumah sakit sebagai organisasi pelayanan kesehatan harus melakukan upaya reformas atau perbaruan organisasi (organizational reform)
3. Membudayakan keselamatan pasien (patient safety) sangat penting, karena budaya mengandung dua komponen yaitu nilai dan keyakinan, dimana nilai mengacu pada sesuatu yang diyakini oleh anggota organisasi untuk mengetahui apa yang benar dan apa yang salah, sedangkan keyakinan mengacu pada sikap tentang cara bagaimana seharusnya bekerja.

\section{CONCLUSIONS}

Sebuah organisasi pelayanan kesehatan harus terus melakukan perubahan ata pembaruan yang mendukung patient safety $k$

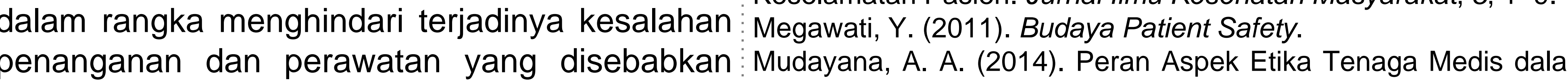
oleh human err. Keberhasilan pembaruan Penerapan Budaya Keselamatan Pasien di Rumah Sakit. organisasi akan tercermin dari terbentuknya Supplemen Majalah Kedokteran Andalas, 37,69-74.

budaya patient safety. Sedangkan keberhasilan Nieva, V. F., \& Sorra, J. (2013). Safety culture assessment: a tool penerapan patient safety akan mampu Paper, W., Rahmadani, A., Padjadjaran, U., \& Rahmadani, A. mencegah atau mengurangi terjadinya human err (2016). Rumah Sakit Pemerintah Sebagai Sebuah Organisasi: yang berakibat pada diagnostic errors dan Struktur, Manajemen Dan Pengembangan Organisasi.

Risdiana, Y. (2016). Analisi Pengaruh Penataan Organisasi Terhadap Kinerja Pegawai pada Dinas Kesehatan Kota Banjar. Universitas Pasundan Bandung.

Sumarni. (2017). Analisis Implementasi Patient Safety Terkait Peningkatan Mutu Pelayanan Kesehatan di Rumah Sakit. Jurnal Ners Dan Kebidanan Indonesia, 5(2), 91-99.

Weaver, S. J., Lubomksi, L. H., Wilson, R. F., \& R., E. (2013). Annals of Internal Medicine Supplement Promoting a Culture Safety as a Patient Safety Strategy. Annals of Internal Medicine, 